\title{
HEAD TRAUMA
}

\section{LONG-TERM ATTENTION PROBLEMS AFTER BRAIN TRAUMA}

Parent ratings of attention problems were obtained at long-term follow-up (average 4 years) after traumatic brain injury (TBI) and compared with ratings of premorbid attention problems shortly after injury, in a study of 132 children (ages 6 - 12 years) at the Ohio State University and Columbus Children's Research Institute and other centers. At follow-up, 46\% of 41 children with severe TBI showed significant attention problems on the Child Behavior Checklist, as compared to $26 \%$ of 50 who had suffered an orthopedic injury (OI). Symptoms consistent with a diagnosis of ADHD (combined subtype) were present in $20 \%$ of the severe TBI group and showed clinically significant attention problems compared to $4 \%$ in the OI group. Measures of executive functions were related to behavioral attention problems. The greater the premorbid difficulties, the more pronounced the differences in the long-term behavioral symptoms (but not cognitive outcomes) in TBI and OI groups. (Yeates KO, Armstrong $\mathrm{K}$, Janusz $\mathrm{J}$ et al. Long-term attention problems in children with traumatic brain injury. J Am Acad Child Adolesc Psychiatry June 2005;44:574-584). (Respond: Dr Keith Owen Yeates, Department of Psychology, Children's Hospital, 700 Children's Drive, Columbus, $\mathrm{OH} 43205$ ).

COMMENT. Premorbid attention problems are exacerbated by TBI, and long-term behavioral symptoms of inattention are related to cognitive deficits in attention and executive functions occurring in association with TBI. Attention problems in children with ADHD are similar to those with TBI, and frontal-subcortical and cerebellar systems implicated in ADHD are often damaged in children with TBI (Gerring J et al, 2000, cited by the above authors).

In 78 preschool children who sustained a mild head injury, the incidence of cognitive deficits including reading difficulties at 6-12 months after injury, at age 6.5 years, was increased compared to a control group with minor injury not involving the head (Wrightson $\mathrm{P}$ et al. J Neurol Neurosurg Psychiatry 1995;59:375-380; Ped Neur Briefs Nov 1995). Even mild head injury, not requiring admission for observation, may result in cognitive deficits and impaired school performance.

\section{ACCIDENTAL AND NONACCIDENTAL HEAD INJURIES IN INFANTS: DISTINGUISHING CHARACTERISTICS}

One hundred fifty infants hospitalized with head injury over a 3-year period, 57 (38\%) due to child abuse, were studied prospectively at the Departments of Pediatric Neurosurgery, Neuro-ophthalmology, and Legal Medicine, CHRU de Lille, France. Mean age at diagnosis was 5.3 months; $103(69 \%)$ boys and $47(31 \%)$ girls. Head circumference was abnormally high, above $97^{\text {th }}$ percentile, in $28(18.7 \%)$ cases. Of the $57(38 \%)$ cases with trauma due to child abuse, 40 involved shaking and 17 involved beating; male to female preponderance was 3.14 . Household accident was the cause of trauma in $55(36.7 \%)$, birth trauma in $21(14 \%)$, and traffic accident in $12(8 \%)$ cases. Perinatal illness (prematurity, long labor etc) found in 54 cases, familial dysfunction such as alcohol or drug abuse in 29 , absent 
signs of impact, and seizures on presentation were significantly correlated with child abuse $(\mathrm{p}<0.001)$. The most frequent admission diagnosis was subdural hematoma $(\mathrm{SDH})$ in 73 $(49 \%)$ cases, skull fracture in $20(13 \%)$, and subarachnoid hemorrhage in $18(12 \%)$. SDH occurred in $81 \%$ of child abuse cases compared to $28 \%$ with accidental trauma. Child abuse was the cause of $64 \%$ of all SDH in this study. Head circumference was not significantly correlated with SDH. Retinal hemorrhage (RE) occurred in 47 (36\%) of 129 cases examined (15 newborns were not included because RE may occur with normal delivery). The sensitivity and specificity of $\mathrm{RH}$ for child abuse were $75 \%$ and $93 \%$, respectively. RE with accidental trauma was always mild, whereas that associated with child abuse was severe. Child abuse was the cause of $90 \%$ of severe morbidity and $71 \%$ of mortality; $17.5 \%$ victims of abuse either died or were in a vegetative state. (Vinchon M, Defoort-Dhellemmes S, Desurmont M, Dhellemmes P, Accidental and nonaccidental head injuries in infants: a prospective study. J Neurosurg (Pediatrics 4) June 2005;102:380-384). (Reprints: Matthieu Vinchon MD, PhD, Service de Neurochirurgie Pediatrique, CHRU de Lille, 59037 Lille, France).

COMMENT. Child abuse is a major cause of infant head trauma in this study, and also, the most frequent cause of death and morbidity from trauma. Infants with a history of perinatal illness or a dysfunctional family are at high risk for child abuse. Severe RE is highly suggestive of child abuse. SDH is more prevalent in cases of abuse compared to accidental head trauma in infants. Child abuse and clinical severity on admission are the main factors influencing outcome of infant head trauma. For a review of non-accidental head injury with particular reference to whiplash shaking injury, see Brown JK, Minns RA. Dev Med Child Neurol 1993;35:849-869, and Progress in Pediatric Neurology II PNB Publ, 1994;pp387-391.

\section{SEIZURE DISORDERS}

\section{IMPACT OF EPILEPSY SURGERY ON MOTOR PERFORMANCE}

The impact of epilepsy surgery on motor performance of 37 children (ages 1 month to 15 years) with refractory seizures was evaluated at the Wilhelmina University Children's Hospital, Utrecht, The Netherlands. Surgery involved hemispherectomy in 14 patients, and temporal (14), frontal (4), parietal (2), or central (2) resection. Presurgical spasticity was present in $17(46 \%)$. Seizures were significantly reduced in frequency in $74 \%$ at 24 month follow-up. Muscle strength and range of motion were decreased, but activities of daily living were improved and need for caregiver's assistance was reduced in the group with spasticity. The movement assessment battery (M-ABC) and gross motor function measure (GMFM) scores were significantly improved $(\mathrm{P}<0.05$ ). (van Empelen R, Jennekens-Schinkel A, Gorter JW et al. Epilepsy surgery does not harm motor performance of children and adolescents. Brain July 2005;128:1536-1545). (Respond: R van Empelen, Department of Paediatric Physical Therapy and Exercise Physiology, University Medical Center, Wilhelmina Children's Hospital, RM. KB 02.056.0, PO Box 850903508 AB, Utrecht, The Netherlands).

COMMENT. Motor function of most children undergoing surgery for epilepsy is not impaired, caregiver's assistance is reduced, and activities of daily living are improved. 